\title{
Projeto de conversações públicas sobre a diferença de opiniōes acerca do Programa Bolsa Família
}

\section{Public conversation project on the difference of opinions about the Bolsa Família Program}

\author{
Pamela Lopes Marques (orcid.org/0000-0003-2700-301X)' \\ Laura Vilela e Souza (orcid.org/0000-0003-0732-8175) ${ }^{2}$ \\ Murilo dos Santos Moscheta (orcid.org/0000-0001-7479-2651) ${ }^{3}$
}

\begin{abstract}
Resumo
O Programa Bolsa Família (PBF) divide opiniões no cenário brasileiro contemporâneo em debates permeados de argumentos abstratos, generalizantes e sentimentos intensos. Neste estudo, busca-se compreender o processo de produção de sentidos em uma facilitação de diálogos, a partir da metodologia do Projeto de Conversações Públicas (PCP), em um encontro entre 10 pessoas com opiniões polarizadas sobre o PBF. A transcrição da audiogravação do encontro foi analisada a partir da perspectiva construcionista social. Os repertórios interpretativos, discursos e posicionamentos relacionados às opiniões a favor e contra o PBF e o feedback dos participantes sobre o encontro foram ressaltados e discutidos.
\end{abstract}

Palavras-chave: Facilitação de diálogos. Construcionismo social. Práticas grupais. Programa bolsa família.

\begin{abstract}
The Bolsa Família Program (PBF) divides opinions in the contemporary Brazilian scenario into debates permeated by abstract arguments, generalizations and intense feelings. This study seeks to understand the process of producing meanings in dialogue facilitation, based on the methodology of the Public Conversation Project (PCP), in a meeting between 10 people with polarized opinions about the PBF. The transcription of the audio recording of the meeting was analyzed from the social constructionist perspective. The interpretative repertoires, discourses and positions related to the opinions for and against the PBF and the participants' feedback on the meeting were highlighted and discussed.
\end{abstract}

Keywords: Dialogue facilitation. Social constructionism. Group process. Family grant program.

\footnotetext{
${ }^{1}$ Universidade de São Paulo, São Paulo, Brasil. E-mail: pamelalopesmarques@hotmail.com

${ }^{2}$ Universidade de São Paulo, São Paulo, Brasil. E-mail: lauravilelasouza@gmail.com.

${ }^{3}$ Universidade Estadual de Maringá, Maringá, Brasil. E-mail: murilomoscheta@me.com.
} 
O Projeto de Conversações Públicas (PCP) oferece uma metodologia para a construção de espaços de diálogo sobre temas polêmicos entre pessoas com perspectivas distintas (Public Conversations Project [PCP], 2011). O PCP foi fundado por uma entidade sem fins lucrativos de mesmo nome, em 1989, na cidade de Watertown, Massachusetts, nos Estados Unidos. As primeiras facilitações de diálogos utilizando essa metodologia nasceram tendo como tema o aborto, como pode ser visto com mais detalhes em Essential Partners (2018). Além desse tema, outros assuntos foram trabalhados por essa instituição, tais como: diferenças religiosas, uso de animais em pesquisa, casamento entre pessoas do mesmo sexo, manejo florestal e conflitos envolvendo o Oriente Médio. Nessa metodologia, a comunicação não é considerada um veículo neutro, mas, sim, permeada de construções socioculturais que influenciam o modo como as pessoas dão sentido à realidade.

Quando modos de pensar distintos entram em contato, é possível que conflitos floresçam e as pessoas se vejam como adversárias à procura das falhas alheias, como se pode ver em debates políticos. Nesses casos, é mais fácil confrontar que ouvir compreensivelmente o interlocutor, e surge ainda o desafio de manter-se atento ao conteúdo e à maneira como ocorre a conversa sem desencadear um clima de tensão (Pearce \& Pearce, 2003). Na busca pela defesa de argumentos em um clima de disputa, há a diminuição da possibilidade de escutar as nuances dos argumentos opostos e o consequente recrudescimento das opiniões pelo uso de descrições generalizadas e estereotipadas. Por esse motivo, os diálogos não acontecem no cotidiano de maneira espontânea, mas carecem de estratégias para sua facilitação (Souza, Oliveira, Silva, Andrade, \& Martins, 2014). Diante disso, este artigo objetiva o estudo do uso da metodologia do PCP sobre o Programa Bolsa Família (PBF), um programa de ações de transferência condicionada de renda a famílias em situação de pobreza e extrema pobreza no Brasil. 


\section{Projeto de conversações públicas}

O PCP propõe uma estrutura de diálogo que conta com conversas individuais prévias ao encontro entre todos os participantes. Nessas conversas, são esclarecidos os pontos a respeito da metodologia proposta, seus objetivos e acordos. Os acordos incluem não interromper e nem criticar as falas dos participantes durante o encontro, além de não se fazer perguntas e nem dar respostas confrontativas, uma vez que o projeto não busca o consenso, mas, sim, motivar as pessoas a contribuir com suas vivências e pontos de vista, para que juntas possam construir novos conhecimentos. No diálogo, os participantes não têm o intuito de convencer, atacar ou interromper o outro, mas permitir que a escuta seja o elemento principal em benefício de um entendimento recíproco, podendo até contribuir para o surgimento de ações conjuntas então inimagináveis (PCP, 2011).

A estrutura do encontro tem início com o lembrete dos acordos da conversa e, em seguida, define-se os tempos de fala para cada questão. Há o pedido para que todos compartilhem experiências pessoais que levaram ao posicionamento de cada um sobre o tema. Esse compartilhamento permite que os participantes percebam como cada opinião possui coerência em uma história conversacional ao longo da vida de cada pessoa. Perceber isso é a oportunidade para os participantes terem empatia com relação a cada história contada, ainda que discordem da opinião que dela deriva. Essa ação favorece a horizontalidade entre os participantes, permitindo que pessoas com menor domínio de argumentos racionais e abstratos participem da conversa de forma mais equilibrada (Moscheta, Souza, Casarini, \& Scorsolini-Comin, 2016).

No momento seguinte, pede-se que os participantes explorem possíveis dúvidas sobre suas próprias opiniões. Espera-se que a pessoa reflita, a fim de perceber em quais momentos é mais difícil manter seu posicionamento e por quais motivos. Essa manobra vai na contramão do que geralmente ocorre em debates, uma vez que valoriza a exploração das incertezas, acreditando que elas possam encorajar novas conversas sobre pontos de interesses comuns. Por fim, há uma discussão facilitada com perguntas de curiosidade entre os participantes (PCP, 2011). 
Essa metodologia apresentou resultados positivos em mais de quinze países e em cerca de trinta e oito estados dos Estados Unidos (Herzig \& Chasin, 2006). No Brasil, o PCP foi utilizado na facilitação de diálogos entre religiosos e LGBTs, alcançando resultados positivos ao favorecer posicionamentos compreensivos a respeito da religiosidade e da diversidade sexual (Moscheta et al., 2016; Moscheta, Souza, \& Santos, 2016).

\section{O Programa Bolsa Família}

Segundo o Ministério do Desenvolvimento Social (Brasil, 2015), o Programa Bolsa Família (PBF) é considerado um dos principais programas de transferência de renda encarregados de promover iniciativas no combate à extrema pobreza e na inclusão social de famílias oprimidas pela miséria. O PBF foi criado em outubro de 2003, com a proposta de diminuir a desigualdade social e de superar a fome por meio do acesso e incentivo a direitos sociais como saúde, educação e assistência social.

O programa se apoia em três eixos principais. O primeiro deles é o complemento da renda familiar (benefício em dinheiro), que varia conforme a renda mensal per capita e composição familiar (quantidade de pessoas, idade, presença de gestantes e nutrizes). 0 segundo eixo é a garantia de acesso a direitos, por meio do cumprimento de condicionalidades que promovam o acesso à educação - crianças e adolescentes de 6 a 17 anos devem estar matriculados na escola e com frequência escolar mensal -, e acesso à saúde - crianças menores de 7 anos devem estar com a vacinação em dia e serem acompanhadas por equipes de saúde ao longo do seu desenvolvimento. As gestantes devem comparecer às consultas médicas e fazer o pré-natal. Por fim, o terceiro eixo é a articulação com outras ações sociais, integrando diversas políticas públicas que visam o desenvolvimento das famílias que se encontram em situação de extrema pobreza.

A introdução do PBF nas políticas públicas do Brasil gerou polêmicas na sociedade por conta da transferência direta de recursos financeiros do Governo para as famílias. Essas polêmicas fomentaram "mitos" com relação ao programa, como por exemplo, o do aumento proposital do número de filhos por parte dos pais beneficiados, no intuito de obterem mais recursos, uma vez que o número de filhos é um dos critérios para o estabelecimento do 
montante. Além disso, também se propagou a crença de que o programa geraria dependência e acomodação de seus usuários, que estariam recebendo um dinheiro sem mérito, e, por isso, sendo desestimulados a buscar emprego (Campello, 2014).

Para Jardim e Flores (2013) a criação desses mitos é resultado de "uma construção social (mesmo que inconsciente) da desmoralização do Estado (e da coisa pública) e, como consequência, dos direitos sociais" (p. 134). A ideia de que políticas distributivas funcionam como esmolas dadas pelo Governo pode decorrer do sentimento implícito de que "o trabalho dignifica o homem", e que, por isso, receber auxílio financeiro sem o trabalho significa, de alguma forma, um aproveitamento ilícito. Segundo Flores (2013), a meritocracia representa uma das principais ideologias defendidas na sociedade moderna, que se caracteriza pela concepção de que a igualdade social existe entre os indivíduos e, portanto, não há necessidade de políticas distributivas.

Na contrapartida às críticas do PBF como projeto assistencialista, autores apontam o Programa como um dos marcos do progresso das conquistas de proteção social no Brasil nos últimos dez anos, contribuindo para assegurar os direitos socioassistenciais das famílias pobres (Colin, Pereira, \& Gonelli, 2014; Jardim \& Flores, 2013). Pereira (2010) defende que os programas de assistência social não devem ser vistos com um caráter de assistencialismo, que apenas distribui benefícios, mas como uma rede que interliga diversos mecanismos que buscam compreender a realidade por meio de planejamentos, estudos, acompanhamentos e avaliações, a fim de garantir a preservação dos direitos humanos.

Diversos estudos surgiram a fim de compreender os reflexos do PBF na população brasileira. Discute-se, por exemplo, a percepção de mulheres beneficiárias acerca das mudanças morais e políticas vivenciadas, enfatizando seu empoderamento e conquista de autonomia após participarem do Programa (Moreira, Ferreira, Lima, \& Ckagnazaroff, 2012; Rego \& Pinzani, 2013). Outros estudos dizem respeito à queda da taxa de abandono escolar de alunos beneficiários (Camargo \& Pazello, 2014); às mudanças positivas na relação entre usuários do Programa e serviços de saúde dos municípios da região Nordeste (Carvalho, Almeida, \& Jaime, 2014); à melhora na qualidade de vida e renda financeira de beneficiados (Santos, Gouveia Junior, Oliveira, Melo, \& Souza, 2014); aos efeitos sobre o planejamento familiar, com a redução do número de filhos nas famílias (Simões \& Soares, 2012); ao 
aumento da oferta de trabalho para mães que fazem parte do PBF (Tavares, 2010); à priorização da educação escolar em detrimento do trabalho infantil dos filhos de famílias beneficiadas (ainda que o Programa não tenha erradicado o trabalho infantil e não apresente isso como uma de suas metas) (Pires \& Jardim, 2014). O jornal Brasil 247 noticiou, em Outubro de 2013, que o PBF venceu o prêmio ISSA (Associação Internacional de Seguridade Social), que equivale ao prêmio Nobel social, por ser reconhecido como um programa pioneiro no combate a redução da pobreza (Bolsa Família, 2013).

Embora o Programa tenha mostrado retornos positivos, o Instituto de Pesquisa Econômica Aplicada (IPEA) prevê um futuro preocupante em relação à extrema pobreza no Brasil. O ajuste fiscal e a baixa expectativa para o cenário da economia e do mercado de trabalho poderão afetar a renda familiar da população mais pobre que recebe o benefício do PBF. Além disso, dados da Pesquisa Nacional por Amostra de Domicílios (PNAD) de 2013 mostraram um breve aumento no percentual da miséria no país, apesar da ampliação da cobertura do PBF (Instituto de Pesquisa Econômica Aplicada [IPEA], 2015). Euzébios Filho (2016) discute o papel do PBF "no processo de precarização da seguridade social e da proteção social básica no Brasil" (p. 258), apontando os efeitos colaterais do Programa, a saber, a dependência financeira de seus usuários e a despolitização da questão social. $\mathrm{O}$ autor acrescenta que, ainda que seja possível perceber a melhoria na condição de vida imediata de pessoas pobres o PBF pouco avançou em termos do enfrentamento das desigualdades sociais brasileiras.

O PBF também se deparou com fraudes e irregularidades entre os beneficiários do Programa. Algumas delas foram reportadas pela mídia, como, por exemplo, o caso da "máfia do Bolsa Família", noticiado pelo jornal Estadão em Outubro de 2015 (Nossa, 2015). A reportagem relatou sobre a investigação realizada pela polícia em municípios amazonenses, onde foram encontrados cartões de beneficiários indígenas do PBF que estavam sob posse de comerciantes da região. Outra reportagem, também noticiada pelo jornal Estadão em Dezembro de 2015 (Porto, 2015), relatou o caso ocorrido num município do interior de São Paulo, onde havia cerca de vinte e cinco beneficiários que não atendiam aos critérios do Programa, mas que conseguiram realizar o cadastramento por meio de declarações falsas. 
Parte da mídia nacional apontou o PBF como um "programa eleitoreiro", cuja intenção seria de manutenção do poder do seu idealizador, o Partido dos Trabalhadores (Giraldi, 2009).

\section{Justificativa e objetivo}

Nos últimos anos, tem-se observado, especialmente nas redes sociais, um acirramento das discussões a respeito do PBF e das políticas distributivas em geral. Essas discussões, boa parte das vezes, acabam por fomentar o ódio entre pessoas que pensam de forma radicalmente diferente sobre o tema. Como exemplo da agressividade que está implicada nas discussões sobre essa temática, pode-se citar a página do Programa Bolsa Família na rede social Facebook, local virtual onde ocorrem trocas de comentários ofensivos entre os que são a favor e contra o Programa.

O fenômeno da polarização das ideias populares no Brasil e as possíveis razões para o acirramento das opiniões com relação a políticas distributivas de renda têm sido objetos de reflexão de diferentes intelectuais, os quais extrapolam o escopo desta pesquisa. 0 interesse aqui é o de estudar os processos grupais de facilitação de diálogo sobre o PBF. Promover diálogos a respeito de questões sociais como o PBF é a oportunidade para que pessoas com opiniões distintas conversem em um ambiente livre de hostilidades, dando abertura para que pensamentos e valores possam emergir e servir como facilitadores na quebra de estereótipos. O uso do PCP, nesse caso, pode ser a oportunidade de compreensão da forma como se dão as diferenças de opiniões nesse tema, e também como essas diferenças são significadas e ressignificadas na conversa. Portanto, o objetivo deste estudo é compreender o processo de produção de sentidos em uma facilitação de diálogos a partir da metodologia do PCP, aplicada a um encontro entre pessoas com opiniões polarizadas sobre o PBF.

\section{Método}

\section{Contexto de realização do estudo e participantes}


O convite para participação no encontro aconteceu a partir da rede de contatos dos pesquisadores, que selecionaram pessoas com inserção em movimentos sociais, militâncias locais (conservadoras e progressistas), conselhos profissionais, profissionais de serviços de assistência social e universidades e empresários da cidade. Foram realizadas entrevistas individuais prévias com cada participante, com o objetivo de avaliar seu grau de envolvimento com o tema do Programa Bolsa Família.

Segundo o PCP (2011), é importante que o grupo seja composto por um número equivalente de pessoas de opiniões contrárias para garantir o equilíbrio da conversa. Centurion, Souza e Moscheta (2016) apontaram que a realização do PCP no Brasil teve como desafio o fato dos participantes, a princípio, aceitarem participar da conversa, mas não se comprometerem a comparecer no dia do encontro. Por esse motivo, foi necessário, neste estudo, criar estratégias a fim de garantir um número equivalente de participantes de ambas as opiniões. Para isso, foram convidados participantes em número superior ao previsto, e negociada a possibilidade de alguns deles ficarem como expectadores caso não houvesse abstenções. Diante da ausência de três participantes, outros três puderam substituí-los, totalizando o número de 10 participantes.

Os participantes são descritos com nomes fictícios a partir das características que apresentaram no grupo e nas entrevistas preparatórias. Os participantes que se declararam favoráveis ao PBF foram: Ana, psicóloga e funcionária pública; Cláudia, socióloga, trabalhadora de serviço de assistência social a crianças e adolescentes; Victória, psicóloga, docente universitária na área de políticas públicas de assistência social; Sidiney, estudante de Direito; Luís, psicólogo, trabalhador da área da educação e assistência social. Os participantes que se declararam contra o PBF: Antônio, empresário, voluntário em projetos sociais, militante de coletivo de direita; Carlos, empresário, ex-coordenador de projetos sociais; Emil, empresário, ministrante de palestras sobre liberalismo econômico; Adalberto, advogado; Fernando, estudante de direito.

Uma dupla de facilitadores especializados na metodologia do PCP conduziu a conversa, que aconteceu em uma sala reservada de uma universidade da cidade. A adaptação da estrutura do PCP para esse encontro levou ao delineamento da conversa a partir dos seguintes momentos: $1^{\text {a }}$ ) Quais experiências pessoais seriam importantes para 
você compartilhar nesse grupo que nos ajudariam a entender sua forma de pensar?; $2^{\mathrm{a}}$ ) Qual é o ponto principal que mais mobiliza você a respeito do tema PBF?; $3^{\mathrm{a}}$ ) Você consegue pensar em algum momento no qual os valores que você defende e que estão relacionados a ser a favor, ou contra, o PBF entrou, ou entra, em conflito com algum outro valor que é igualmente importante pra você?; $4^{\mathrm{a}}$ ) Há alguma pergunta de curiosidade legítima que você gostaria de perguntar a alguém que pensa muito diferente de você?; $5^{\mathrm{a}}$ ) Como foi participar dessa conversa?

\section{Processo de construção e análise do corpus}

O encontro de PCP foi audiogravado, totalizando duas horas de áudio, transcritas integral e literalmente. A análise da produção de sentidos, na perspectiva construcionista social, compreende sentido como um empreendimento coletivo e interativo em que as relações, atravessadas por sua historicidade e valores culturais, conformam os termos a partir dos quais as pessoas significam os acontecimentos do mundo ao seu redor (Spink, 2010). Buscando entender os diferentes sentidos produzidos no encontro de PCP sobre o PBF, foi utilizada a proposta de Spink e Medrado (2013), que analisa a produção de sentidos em sua complexidade, em uma análise de três tempos. No Tempo Longo é possível identificar os discursos que sustentam um determinado sentido sobre o tema. São os conhecimentos e visões de mundo produzidos pelo senso comum, religião, ciência e tradições. $\mathrm{Na}$ análise de Tempo Vivido é possível reconhecer os repertórios interpretativos utilizados por cada pessoa a partir de sua história de vida e socialização. Repertórios são "o conjunto de termos, descrições, lugares-comuns e figuras de linguagem que demarcam o rol de possibilidades de construções discursivas" (p. 28). O Tempo Curto demarca os posicionamentos das pessoas na conversa.

Para a análise dessas temporalidades, a transcrição foi organizada conforme proposto por Brigagão, Nascimento, Tavanti, Piani e Figueiredo (2014), em formato de tabela, cujas colunas compreendam individualmente cada participante e os coordenadores, enquanto a sequência da transcrição integral do grupo é colocada dentro das colunas. Isso permite identificar os sujeitos e suas respectivas falas durante a conversa. Também foram 
destacados em diferentes cores os repertórios interpretativos, posicionamentos e discursos na fala de cada um dos participantes, marcando sua relação com a construção de um sentido específico sobre o PBF. Por exemplo, os posicionamentos de Ana, como "alguém que conhece pessoas que passaram por dificuldades e precisaram de ajuda e alguém que conhece e convive com pessoas pobres" (tempo curto), apareceram quando ela fez uso do "discurso da valorização dos direitos humanos" (tempo longo) e enfatizou repertórios interpretativos tais como "dificuldade", "privilégios", "ajuda", "escolhas" (tempo vivido). Nesse momento, o sentido construído foi o de que o PBF "é para quem não tem condições de escolher e que é um programa que empodera a pessoa".

Esta pesquisa foi aprovada pelo Comitê de Ética em pesquisa com seres humanos (CAAE n 63638716.0.0000.5407 aprovado pelo Comitê de Ética em Pesquisa da FFCLRPUSP). Todos os cuidados éticos preconizados para pesquisa com seres humanos foram tomados, além dos cuidados na elaboração dos diálogos empreendidos nas conversas preparatórias.

\section{Resultados e discussão}

\section{Primeiro momento}

Nesse momento, os sentidos sobre o PBF foram construídos a partir da exploração das histórias pessoais que contribuíram para a construção da opinião dos participantes. Foi possível, a partir do formato de conversa, a percepção de que: 1) histórias de vida semelhantes podem levar a opiniões antagônicas; 2) é possível encontrar na escuta da história do outro elementos que posicionam o ouvinte para além das polaridades do "totalmente a favor ou contra".

A maior parte dos participantes evocou personagens de suas famílias para sustentar seus posicionamentos. Ana, que deu início à conversa, citou a história do seu pai como alguém que tem uma importância significativa na construção da sua opinião a favor ao PBF, descrevendo-o como um imigrante do Nordeste que veio para o estado de São Paulo em busca de melhores condições de vida, passando por dificuldades financeiras e precisando da ajuda de outras pessoas para conseguir reorganizar sua vida. 
A partir disso, outras histórias emergiram no grupo, como a de Antônio, que conta sobre o período em que sua mãe se divorciou e se tornou uma das provedoras do lar; a de Luís, que conta a trajetória de vida de sua mãe, que também veio imigrada do Nordeste junto com sua ama-de-leite, foi posteriormente adotada e viveu em um quarto de empregada até conseguir se tornar uma empreendedora; a de Adalberto, cujo pai era filho de imigrantes portugueses e precisou sacrificar o estudo para trabalhar e sustentar seus quatro irmãos, uma vez que seu pai, avô de Adalberto, faleceu quando ainda era muito jovem.

Nesse momento do grupo, os principais repertórios interpretativos utilizados pelos participantes a favor do PBF (“dificuldades", "ajuda”, "privilégios", "escolhas", "igualdade social", "perseverança") estavam relacionados com a importância de se receber ajuda em momentos difíceis, e com a ideia de que apenas algumas pessoas têm privilégios, o que consequentemente as possibilitam fazer determinadas escolhas que os desprivilegiados não poderiam. Esses repertórios estavam ligados a discursos contrários à meritocracia, priorizando a coletividade ao invés do indivíduo. Os principais sentidos construídos sobre o PBF foram de que se trata de um programa feito para quem não teve condições de escolher e de que favorece o empoderamento pessoal ao possibilitar uma melhora na qualidade de vida. Esses sentidos posicionaram esses participantes como pessoas que não aceitam a desigualdade social e, por isso, sensibilizam-se com histórias de vida de pessoas que sofrem diretamente com essa problemática.

Com relação aos participantes com opinião contrária ao PBF, no primeiro momento da conversa, os repertórios que circularam em suas falas estavam relacionados ao reconhecimento do labor como um valor moral, fazendo referência a ele por meio de palavras como: "batalha", "esforço" e "empenho". Ligados a esses repertórios, estavam o discurso focado nas potencialidades individuais e o discurso de crítica ao assistencialismo, que por sua vez produziram sentidos do PBF tais como: é uma ajuda que não ameniza a pobreza, é facilmente burlado, não implica as pessoas a valorizarem o esforço do trabalho. Esses sentidos posicionaram os participantes como pessoas que valorizam o trabalho e, por isso, preferem ajudar aqueles que querem mudar de vida, sendo esta uma ajuda permeada de condicionalidades, pois o contrário se caracterizaria como caridade. 
As histórias escolhidas por essas pessoas para partilharem com o grupo estavam povoadas de personagens esforçados e batalhadores, que conseguiram sair de uma situação de pobreza graças ao seu empenho pessoal. O significado do trabalho para essas pessoas demonstrou ser para além de uma atividade profissional, um conjunto de valores ensinados pelas suas famílias, como é visto na fala de Carlos:

[...] O meu avô era um comerciante, mas que tinha 11 filhos, então acontecia que meu pai trabalhava pra poder pagar a universidade do meu irmão mais novo. Então assim, essa questão de trabalho dentro de casa, esforço, empenho, sempre foi muito, muito, muito, muito pregado, né? Pra mim e pros meus irmãos [...].

A ideia de que "o trabalho dignifica o homem" está atrelada ao discurso da meritocracia, que pode ser definida como um conjunto de valores que estabelece uma relação direta entre o nível social do indivíduo e o mérito. Nesse contexto, o mérito é o reconhecimento público das ações e conquistas de caráter individual, o que torna a meritocracia uma das principais ideologias da sociedade moderna (Barbosa, 1999).

Apesar dos participantes contrários ao PBF terem narrado histórias pessoais semelhantes às dos favoráveis, o modo como cada um significou essas vivencias foi distinto, conforme percebido e destacado por Luís, que é a favor do PBF: “[...] Então é uma vida de contradições, né? Parecida com a vida que a gente viveu, com as mesmas situações, mas a construção da minha posição é diferente de alguns, provavelmente".

Essa percepção de que histórias de vida semelhantes podem levar a opiniões distintas é um dos efeitos observados nos grupos de PCP. Esse reconhecimento traz a possibilidade de que os participantes tenham maior empatia entre si e percebam como sua história poderia ter levado a opiniões e valores morais distintos: ser a favor do PBF pela valorização do empoderamento que ele oferece ou ser contra pela valorização da meritocracia. Percebe-se aí um movimento de junção do tempo vivido e do tempo longo, em que o discurso da meritocracia está ligado a narrativas de histórias pessoais que ressignificam esses conteúdos históricos ao longo do processo de socialização (Spink, 2010).

Chamou a atenção o modo como Antônio construiu sua opinião no grupo, pois apesar de identificar-se como um participante contrário ao PBF, ele se aproximou do 
pensamento daqueles que são a favor do PBF. Essa aproximação aconteceu em decorrência dos momentos da sua história de vida em que se encontrou necessitado de outras pessoas, por sofrer de uma doença crônica que o limita fisicamente. Na fala de Antônio, sua dependência da ajuda alheia o leva a entender situações nas quais o próprio esforço não é suficiente para que uma pessoa supere certas dificuldades:

[...] Se eu não tiver um carro, alguém pra me dar um banho... o que eu faço não cobre esses custos. Meus amigos fazem uma "vaquinha", e eu tenho ajuda disso, se não eu não conseguiria. Então por isso que eu falo, mais ou menos o que a Ana falou, eu acho que aqui a gente vai encontrar pontos que assim, como falou no começo, nem que seja totalmente contra e nem totalmente a favor. (Antônio)

\section{Segundo momento}

No segundo momento do grupo, há o pedido para que os participantes expressem de forma direta suas opiniões, quando não é comum ocorrer movimentos significativos de aproximação entre as polaridades em termos da produção de sentidos sobre o tema, como também foi visto nesse grupo.

Os principais repertórios interpretativos utilizados pelos participantes a favor do PBF (“plural”, "ajuda", "desigualdade social”, "reforma política”, "repasse de verba”) estavam permeados de problematizações acerca do gerenciamento das políticas públicas e os efeitos de uma má administração nas políticas de proteção social e, consequentemente, na incidência de situações de risco pessoal e social para a população. Esses repertórios, por sua vez, estavam sustentados pelo discurso socialista e pelo discurso em prol dos direitos humanos e das políticas de proteção social. Tais discursos levaram esses participantes a se posicionarem como pessoas que se sensibilizam com a realidade das classes socioeconômicas mais baixas, principalmente quando existem reflexos positivos do PBF sobre elas, compreendendo a desigualdade social como produto do sistema econômico atual (Castro, Walter, Santana, \& Stephanou, 2009). Os sentidos sobre o PBF produzidos são de que o programa ajuda a reduzir a desigualdade social gerada pelo sistema capitalista, sem 
por isso se caracterizar como assistencialista, e, sim, como porta de entrada para os serviços ofertados pelos Sistema Único de Assistência Social (SUAS).

Os principais repertórios que emergiram das falas dos participantes com opinião contrária ao PBF tiveram relação com a origem do PBF, relacionando-o a interesses políticos ("eleitoreiro", "voto de cabresto", "dependência"). Tais repertórios eram atravessados pelo discurso do neoliberalismo e do assistencialismo, produzindo sentidos sobre o PBF ser um programa retrógrado, destinado ao controle eleitoral. O Estado, tomado como totalitário, justificaria o controle da população por meio da implantação de um programa de assistência social. Daí o entendimento de que o PBF acarreta o enfraquecimento do desenvolvimento social e econômico do país, pois "acomoda" os beneficiários, tornando-os dependentes do governo e perpetuando o ciclo da pobreza.

Nesse momento do grupo, destaca-se o fato das pessoas que eram a favor do PBF situarem seus argumentos a partir de sua atuação profissional na área socioassistencial. Luís, por exemplo, é alguém que trabalha diariamente com beneficiários do PBF e, portanto, sustenta sua opinião a favor do programa, a partir de sua vivência profissional:

[...] E isso me pega na questão da justiça, pessoas que eu conheço e que se beneficiam, que vivem melhor com isso. É uma ajuda com impacto muito pequeno nas contas públicas, se pensarmos em outras questões públicas [...]. (Luís)

A reflexão sobre esses lugares de fala no grupo garante que se leve em conta a diferença dos lugares ocupados por cada participante quando definem seus pontos de vista. Uma opinião polarizada pode ser calcada em informações propagadas pela mídia, pelos entendimentos do senso comum ou pelo contato cotidiano com o tema. No encontro, não foi possível, ainda que os pesquisadores tivessem feito esforços nesse sentido, a presença de pessoas beneficiárias ou ex-beneficiárias do PBF, que narrariam suas histórias a partir de um lugar bastante distinto daqueles que trabalham com o tema ou que não tiveram vivências pessoais sobre ele. Castro, Walter, Santana e Stephanou (2009), em um estudo sobre a percepção da população brasileira sobre o PBF, afirmam que as pessoas que conhecem pessoalmente beneficiários do programa tendem a ter uma opinião positiva sobre o mesmo, ao passo que aquelas que não conhecem nenhum beneficiário se mostram cautelosas e 
críticas. Os autores defendem que entender a opinião da sociedade sobre qualquer política pública é elemento fundamental para a construção de sua efetividade.

No caso das pessoas contrárias ao PBF, nesse segundo momento do encontro, o discurso da meritocracia esteve fortemente presente, conforme ilustrado na fala de Carlos:

Uma pessoa que cata latinha na rua, ela consegue maiores proventos do que o próprio Bolsa Família, certo? Só que eu entendo que a pessoa, quando cata latinha, ela sabe o quanto é difícil catar uma latinha, ela trabalha pra conseguir aquilo, e pra ter um recurso no final, né? Então como depende de um esforço, ela sabe dar muito mais valor pra aquilo que ela tá recebendo, certo?

A noção da responsabilidade individual está relacionada ao pensamento neoliberal e ao valor moral de que as pessoas devem ser batalhadoras, capazes de superar adversidades, sejam elas econômicas ou sociais; e, assim, alcançar conquistas com seu próprio esforço, sem precisar do auxílio do Estado (Castro et al., 2009). Daí o sentido dado por Carlos de que "repasse de verba não implica as pessoas a valorizarem o esforço, o trabalho e consequentemente o dinheiro". Nessa ótica, o indivíduo tem o trabalho como um valor, sendo responsável por suas escolhas e destino; a igualdade está relacionada ao discurso da meritocracia, no qual todos têm oportunidades iguais (Barbosa, 1999). Nessa visão, o contexto socioeconômico em que a pessoa nasceu não interferiria na sua busca por "vencer na vida", uma vez que ela é responsável pelo seu destino, e deve, então, por esforço próprio, ser capaz de superar quaisquer adversidades de caráter social (Oliveira, 2014).

Além disso, os participantes contrários ao PBF também atribuíram o sentido ao programa como eleitoreiro e de caráter assistencialista. Partindo do discurso neoliberal, que prevê a mínima participação do Estado, autonomia e liberdade do indivíduo, compreende-se o PBF como sendo assistencialista e populista. Por se tratar de um programa de repasse direto de verba, o interpretam como uma estratégia para manipular o eleitorado em favor do partido político que o instituiu, como numa espécie de "compra de votos" legalizada (Biroli \& Mantovani, 2010). As falas de Emil e Carlos ilustram esses aspectos:

Todos que eu conversei no Nordeste [referindo-se ao contato que teve com pessoas de baixa renda em ação de voluntariado que teve no Nordeste], todos, sem exceção, 
"você prefere o Bolsa Família ou que o custo de vida seja mais baixo?", "custo de vida mais baixo". (Emil)

E aí o programa, ele acaba sendo manipulado, ele é moeda de troca por parte do Governo, e das pessoas que detém o domínio do Bolsa Família, no caso do Estado, do Governo, então ele quer, é o cabresto, né? (Carlos)

\section{Terceiro momento}

No terceiro momento da conversa, os participantes foram convidados a problematizar suas próprias opiniões, a encontrar possíveis zonas cinzas em seus modos de pensar. Todavia, poucos realizaram esse movimento de buscar na própria opinião nuances que poderiam complexificar a discussão do tema.

Foi possível perceber que os repertórios que se destacaram nas falas dos participantes a favor ao PBF ("sistema econômico", "assistência social”, "denúncia", "socialismo", "capitalismo") estavam relacionados aos sistemas econômicos capitalista e socialista, partindo da premissa de que o atual modelo favorece a desigualdade socioeconômica enquanto que o socialismo é visto como uma alternativa frente a essa problemática. Os participantes trouxeram como sentido do PBF o fato de ele não se resumir apenas a um programa de repasse de verba, demonstrando conhecimento acerca da sua estrutura, principalmente no que diz respeito às condicionalidades que devem ser cumpridas pelo beneficiário que faz parte do mesmo. Os discursos destacados por esses participantes foram aqueles em prol dos direitos humanos e das políticas de proteção social e contra o capitalismo, revelando uma perspectiva diferente dos que são contrários ao PBF, ao compreenderem o programa como um direito social e, não, como um meio de arrecadação de votos (eleitoreiro).

Os participantes Claudia, Victória e Sidney reconheceram que o mesmo apresenta casos de fraudes. Apesar dessa questão representar a zona cinza de suas opiniões, eles compreendem que não se trata de um problema do programa em si e da sua estrutura, mas, sim, de uma falha do próprio Governo. Eles entendem que, para haver as fiscalizações que inibiriam essas fraudes, seria necessário um número maior de profissionais para realizar tal 
tarefa, algo que nem sempre é possível. Já os participantes Luís e Claudia não identificaram uma zona cinza em suas opiniões, que foram sustentadas principalmente pelo uso do discurso anticapitalista. Para eles, é difícil não ser totalmente a favor do PBF, por acreditarem que de nada adianta acabar com o programa se o próprio sistema econômico e o Governo não favorecem a melhoria de vida das classes desfavorecidas:

[...] Eu sou a favor, eu não acho que tem que abolir o programa. Ou você abole o programa ou você muda o sistema junto porque uma coisa não vai sem a outra, eu acho que tem que ser junto, assim. (Claudia)

Poucos participantes contrários ao PBF apresentaram zonas cinzas em suas opiniões, repetindo sua certeza de que o programa era algo ruim, visto que sua criação teve como objetivo principal angariar votos da população, e não amenizar os danos causados pela pobreza ("eleitoreiro", "esmola", "carregar os outros"). Os participantes Antônio, Adalberto e Fernando, que conseguiram encontrar uma zona cinza, disseram concordar que o Governo ofereça um meio de amenizar os efeitos da desigualdade social, e admitiram o PBF como uma alternativa para isso, já que no momento não existem outras.

Em estudo sobre o uso do PCP, Souza e Moscheta (2016) fazem uma reflexão sobre os aspectos éticos no uso dessa metodologia. Eles argumentam que, a depender das relações de poder construídas socialmente em torno de uma dada temática polêmica, diferentes são os riscos, as possibilidades, as implicações e a disposição das pessoas no grupo para assumir suas incertezas e reconhecer os pontos frágeis de suas opiniões. No caso do encontro sobre o PBF, não havia uma previsibilidade que impedisse os participantes de se colocarem em posição de vulnerabilidade. Contudo, para alguns deles, parece ter sido importante manter sua posição inicial, para que a diferença entre subgrupos permanecesse marcada. Essa diferença foi sendo construída sobre a distinção entre aqueles que defendem o socialismo e aqueles que defendem o modelo neoliberal, ainda que essa distinção não abarcasse a posição de todos no grupo. Pareceu que, para algumas pessoas presentes, contrárias ao PBF, como Luís, o encontro proporcionou, pela primeira vez, a oportunidade de se conversar com alguém que se declara abertamente socialista. Essa divisão dentro do grupo repete, de certa forma, a divisão propagada pela mídia no país, que posiciona as pessoas de forma que, ao ocupar um dos "lados", automaticamente adotam todo um pacote 
pré-definido de ideias sobre os variados assuntos sociais, o que leva à homogeneização e criação de estereótipos grupais. Nesse sentido, um dos limites do PCP, ao estruturar a conversa a partir da polarização das opiniões, é o de priorizar as falas que abordem essa polaridade ao invés de favorecer a maior exploração das nuances de opinião de um mesmo grupo. A própria forma como são apresentados os resultados da pesquisa neste texto mantem essa separação e favorece essa homogeneização, ao mencionar em bloco as pessoas contrárias e favoráveis ao programa.

Um ponto que chamou atenção durante as falas dos participantes contrários ao PBF foi o desconhecimento das condicionalidades do PBF e do seu funcionamento. Para Campello (2014), a desinformação contribui para que pessoas contrárias ao PBF fomentem a crença de que o programa gera dependência e acomodação de seus usuários. Ao mesmo tempo, as próprias condicionalidades são criticadas por pessoas a favor do PBF, pois elas responderiam a um ideal neoliberal de ações compensatórias que não levariam a mudanças no sistema econômico e social como um todo (Trevisani, Burlandy, \& Jaime, 2012).

\section{Quarto momento}

No quarto momento da conversa, abriu-se a oportunidade de os participantes fazerem perguntas de curiosidade uns aos outros. A proposta do PCP para esse momento de conversa é possibilitar aos participantes perguntar sobre aspectos que, usualmente, não conseguem explorar em conversas sobre o tema, devido ao clima de animosidade que essas conversas suscitam e pelo interesse em elaborar perguntas que servem apenas para desbancar o argumento adversário. Poucas perguntas foram feitas e talvez isso se justifique pela dificuldade de estar na situação nova de explorar as diferenças a partir da curiosidade, e, não, do paradigma certo-errado, que nos convida a conversas atravessadas pela retórica e persuasão. Ana questionou: "[...] Mas eu queria te perguntar, se você conhece pessoas que fizeram o trabalho de oferecer algumas coisas prontas e que tiveram um retorno e que as pessoas fizeram sim alguma coisa [...] que a pessoa sendo ajudada se ajudou".

Ana se referiu, em sua pergunta, ao trabalho de voluntariado de Carlos, pelo qual o empresário financiava ações de assistência em regiões pobres do Nordeste. Carlos se 
decepcionou ao ver que, mesmo com a ajuda dispensada, as pessoas não melhoravam sua condição, e então concluiu que a oferta de ajuda não deve vir pronta. Ana pareceu querer explorar possíveis exceções ao cenário que levou Carlos à sua conclusão.

O sentido implícito sobre o PBF na fala de Ana é: ainda que a oferta de ajuda seja "algo pronto", disso não decorre necessariamente que a ajuda gere a acomodação das pessoas. O repertório "retorno" produz o sentido do PBF como um investimento, e posiciona seus beneficiários na obrigação de mostrar "resultados", dentro de uma lógica discursiva meramente financeira dos investimentos sociais.

Luís questionou Emil:

[...] Eu acho que é, de curiosidade, é, talvez o Emil possa me ajudar, porque eu não quero confrontar. É possível ser liberal capitalista e se aproximar do que a gente [a favor do PBF] tá querendo dizer aqui? [...] Só quero entender, sem confronto. (Luís) Essa pergunta parece ter sido feita na direção de empreender aproximações de pensamento, mesmo na diferença de opiniões. Ao que Emil respondeu:

Primeiro, quando a gente fala em Liberalismo econômico não é um pensamento 'é pode tudo, vai lá faz tudo, libera geral', não é esse o conselho. Quando a gente fala em liberalismo econômico, parte-se do princípio em que as pessoas tem liberdades de escolha [...] por que ele (Estado) fala em justiça social e ele não respeita a individualidade e a história de cada um. (Emil)

O sentido sobre o PBF nessa fala é de um programa no qual o Estado impede a liberdade de escolha dos indivíduos. O discurso do liberalismo econômico, explicitado na fala de Emil, contrapõe-se a um Estado de Bem-estar social, com poder econômico e político de tomar decisões em prol do cuidado com a população. Nessa perspectiva, defende-se a liberdade individual em oposição ao controle estatal. Uma possível aproximação entre o pensamento de Luís e Emil parece se dar na rejeição de uma posição extrema, na qual o indivíduo não teria nenhuma ajuda e o Estado não teria nenhuma função, um "libera geral". A defesa de algumas seguranças estatais pareceu ser um ponto de interesse comum entre os participantes.

No feedback sobre a conversa, os participantes a favor do PBF enfatizaram a importância do exercício de escuta e o modo como ele favoreceu o respeito e diminuiu os 
riscos de um confronto. Muitos disseram que não aceitariam participar desta pesquisa se, ao invés de um diálogo, fosse proposto um debate. Isso revela o quão significativo é esse formato de conversa. Apesar de os participantes afirmarem não terem apreendido novos conteúdos, o modo como conversaram e perceberam os demais participantes foi uma novidade. Alguns participantes frisaram o desejo em dar continuidade à conversa. Carlos chegou a fazer uma proposta de criação de um grupo no aplicativo "WhatsApp" para que todos pudessem continuar a discutir ideias que não foram possíveis de serem aprofundadas em apenas um encontro.

\section{Considerações finais}

O PCP assume a estruturação da conversa (com acordos prévios, tempo de fala e perguntas específicas) como o elemento que permite que uma comunicação não violenta seja possível. Porém, essa estrutura limita as possibilidades conversacionais. Aplicada ao caso do PBF, essas possibilidades foram delimitadas: 1) pela percepção de que histórias de vida semelhantes, permeadas de valores morais equivalentes, podem levar à defesa de opiniões e discursos distintos; 2) pela percepção de que os lugares de fala são distintos conforme o lugar que se ocupa em relação ao tema; 3 ) pela oportunidade de os participantes lidarem com o contraditório ao verem suas próprias opiniões sendo problematizadas pelos que pensam diferente. Não foi possível, como notaram alguns participantes, a exploração mais detalhada das opiniões, ainda que, em alguns momentos, esse interesse por aprofundamento parecesse marcado pelo desejo de uma retórica de convencimento e, não, de curiosidade sincera, como pretende o PCP.

As apostas do PCP nos benefícios dialógicos da pergunta de zona cinza e perguntas "curiosas" (terceiro e quarto momento) estiveram um tanto frustradas nesse encontro, ainda que seu uso em encontros de PCP com outras temáticas polêmicas tenham se mostrado profícuas (Moscheta et al., 2016; Moscheta, Souza, \& Santos, 2006). Isso pode ter sido uma especificidade desse grupo de participantes, o que tornaria necessário outros estudos que explorassem esse aspecto. Além disso, o grupo pode ter sofrido influência do momento histórico do país na oportunidade de realização da pesquisa, em que o PBF se apresenta 
como uma das principais bandeiras políticas do partido governante, o Partido dos Trabalhadores, com o agravante da crescente polarização entre a população contrária e favorável ao Governo.

Os resultados deste estudo apontam para a direção do potencial de outros investimentos nessa metodologia. A aproximação de pessoas que não conversariam entre si no cotidiano, como no caso de empresários que nunca haviam conversado com socialistas, é um efeito positivo desse método. A virtude dessa proposta esteve mais relacionada, nesta pesquisa, com a possibilidade de um modo diferente de comunicação, e não propriamente com a construção de novos sentidos sobre o tema em termos de conteúdos sobre as opiniões apresentadas. Ainda assim, a motivação dos participantes para novas conversas, para que pudessem aprofundar e detalhar pontos de vista com a ajuda dos facilitadores, mostra um desejo por espaços de maior escuta e troca. Seria interessante que novos encontros fossem delineados com participantes que estão efetivamente envolvidos na construção de políticas públicas e que pensam de forma diferente uns dos outros, ou em cenários nos quais pessoas de grupos discordantes estejam em situações de embates mais diretos.

\section{Referências}

Barbosa, L. (1999). Igualdade e meritocracia: a ética do desempenho nas sociedades modernas. Rio de Janeiro: FGV Editora.

Biroli, F., \& Mantovani, D. (2010). Disputas, ajustes e acomodações na produção da agenda eleitoral: a cobertura jornalística ao Programa Bolsa Família e as eleições de 2006. Opinião Pública, 16(1), 90-116. https://doi.org/10.1590/S0104-62762010000100004

Bolsa Família vence o prêmio ISSA, o Nobel social. (2013, 15 de outubro). Brasil 247. https: / www.brasil247.com/pt/247/brasil/ 1 17868/Bolsa-Fam\%C3\%ADlia-vence-pr \%C3\%AAmio-ISSA-o-Nobel-social.htm

Brasil, República Federativa do Brasil. Ministério do Desenvolvimento Social. (2015, 1 de julho). Bolsa Família: o que é. Secretaria Especial do Desenvolvimento Social. http://mds.gov.br/assuntos/bolsa-familia/o-que-e

Brigagão, J. I. M., Nascimento, V. D., Tavanti, R. M., Piani, P. P., \& Figueiredo, P. (2014). Como fazemos para trabalhar com a dialogia: a pesquisa com grupos. In M. J. Spink, J. I. M. Brigagão, V. L. V. Nascimento, \& M. P. Cordeiro (Orgs.), A produção da informação na pesquisa social: compartilhando ferramentas (pp. 73-96). Rio de Janeiro: Centro Edelstein de Pesquisas Sociais. 
Camargo, P. C., \& Pazello, E. T. (2014). Uma análise do efeito do programa bolsa família sobre o desempenho médio das escolas brasileiras. Economia Aplicada, 18(4), 623https://doi.org/10.1590/1413-8050/ea388

Campello, T. (2014). Uma década derrubando mitos e superando expectativas. In M. C. Neri, \& T. Campello (Orgs.), Programa Bolsa Família: uma década de inclusão e cidadania (pp. 13-14). Brasília, DF: Ipea. http://www.mds.gov.br/webarquivos/publicacao/bolsa_familia/Livros/ Bolsa10anos_Sumex_Port.pdf

Carvalho, A. T., Almeida, E. R., \& Jaime, P. C. (2014). Condicionalidades em saúde do programa Bolsa Família - Brasil: uma análise a partir de profissionais da saúde. Saúde e Sociedade, 23(4), 1370-1382. https://doi.org/10.1590/S0104-12902014000400020

Castro, H. C. O., Walter, M. I. M. T., Santana, C. M. B., \& Stephanou, M. C. (2009). Percepções sobre o Programa Bolsa Família na sociedade brasileira. Opinião Pública, 15(2), 333355. https:// doi.org/10.1590/S0104-62762009000200003

Centurion, N. B., Souza, L. V., \& Moscheta, M. (2016). Participación en conversaciones públicas: homosexualidad y matrimonio entre personas del mismo sexo. Quaderns de Psicologia, 18(2), 59-70. https://doi.org/10.5565/rev/qpsicologia.1328

Colin, D. R. A., Pereira, J. M. F., \& Gonelli, V. M. M. (2014). Trajetória de construção da gestão integrada do sistema único de assistência social, do cadastro único e do programa bolsa família para a consolidação do modelo brasileiro de proteção social. In M. C. Neri, \& T. Campello (Orgs.), Programa Bolsa Família: uma década de inclusão e cidadania (pp. 1718). Brasília, DF: Ipea. http://www.mds.gov.br/webarquivos/publicacao/bolsa_familia/Livros/ Bolsa10anos_Sumex_Port.pdf

Essential Partners. (2018). About us: History. Essential Partners. https://www.whatisessential.org/history

Euzébios Filho, A. (2016). Sobre ideologias e programas de transferência de renda no Brasil. Psicologia \& Sociedade, 28(2), 257-266. https://doi.org/10.1590/180703102016 v28n2p257

Flores, S. M. (2013). Representações sociais do programa bolsa família na mídia. Anais da XI Semana de Ciências Sociais da UFSCar (pp. 175-184). São Carlos: UFSCar. http://www.semanasociais.ufscar.br/wp-content/uploads/2014/03/Anais-sociaiscom-artigo-141.pdf

Giraldi, R. (2009, 17 de fevereiro). Patrus Ananias rebate Jarbas e nega caráter eleitoreiro do Bolsa- Família. Folha de São Paulo. https://www1 folha.uol.com.br/poder/2009/02/505233-patrus-ananias-rebatejarbas-e-nega-carater-eleitoreiro-do-bolsa-familia.shtml

Herzig, M., \& Chasin, L. (2006). Fostering dialogue across divides: nuts and bolts guide from the Public Conversations Project. Watertown: Public Conversations Project. https: / www.whatisessential.org/sites/default/files/Fostering\%20Dialogue \%20v2015.pdf

Instituto de Pesquisa Econômica Aplicada. (2015). Políticas sociais: acompanhamento e análise. Brasília, DF: Ipea. 
http://www.ipea.gov.br/portal/images/stories/PDFs/politicas_sociais/ bps_23_14072015.pdf

Jardim, M. C., \& Flores, M. S. (2013). Programa Bolsa Família: enquadramento cognitivo dos direitos sociais. In M. C. Jardim (Org.), Estado e mercado no Brasil contemporâneo: a produção de sentidos a produção de alianças (pp. 125-152). São Paulo: Cultura Acadêmica.

http://master.fclar.unesp.br/Home/Instituicao/Administracao/DivisaoTecnicaAcademica /ApoioaoEnsino/LaboratorioEditorial/serie-temas-em-sociologia-n.6.pdf\#page $=126$

Moreira, N. C., Ferreira, M. A. M., Lima, A. A. T. F. C., \& Ckagnazaroff, I. B. (2012). Empoderamento das mulheres beneficiárias do Programa Bolsa Família na percepção dos agentes dos Centros de Referência de Assistência Social. Revista de Administração Pública, 46(2), 403-423. https://doi.org/10.1590/S0034-76122012000200004

Moscheta, M., Souza, L. V., Casarini, K., \& Scorsolini-Comin, F. (2016). Da (im) possibilidade do diálogo: projeto de Conversações Públicas e questões LGBT. Psicologia \& Sociedade, 28(3), 516-525. https://doi.org/10.1590/1807-03102016v28n3p516

Moscheta, M. S., Souza, L. V., \& Santos, M. A. (2016). Health care provision in Brazil: a dialogue between health professionals and lesbian, gay, bisexual and transgender service users. Journal of Health Psychology, 21(3), 369-378. https://doi.org/10.1177/1359105316628749

Nossa, L. (2015, 4 de outubro). Polícia investiga máfia do Bolsa Família. Estadão. https://politica.estadao.com.br/noticias/geral,policia-investiga-mafia-do-bolsafamilia-, 1774360

Oliveira, M. F. D. (2014). Meritocracia e responsabilidade individual no igualitarismo de John Rawls e Ronald Dworkin [Tese de Doutorado, Universidade de São Paulo]. Biblioteca Digital de Teses e Dissertações da USP. https://doi.org/10.11606/D.8.2014.tde$12052015-095742$

Pearce, W. B., \& Pearce, K. A. (2003). Taking a communication perspective on dialogue. In R. Anderson, L. A. Baxter, \& K. N. Cissna (Eds.), Dialogue: theorizing difference in communication studies (pp. 39-56). Thousand Oaks: Sage.

Pereira, P. A. P. (2010). A assistência social prevista na Constituição de 1988 e operacionalizada pela PNAS e pelo SUAS. SER Social, (20), 63-84. https://doi.org/10.26512/ser_social.v0i20.12767

Pires, F. F., \& Jardim, G. A. S. (2014). Geração bolsa família escolarização, trabalho infantil e consumo na casa sertaneja (Catingueira/PB). Revista Brasileira de Ciências Sociais, 29(85), 99-112. https://doi.org/10.1590/S0102-69092014000200007

Porto, G. (2015, 11 de dezembro). PF indica 25 beneficiários do Bolsa Família por suspeita de

fraude. Estadão. https://politica.estadao.com.br/noticias/geral,pf-indicia-25beneficiarios-do-bolsa-familia-por-suspeita-de-fraude, 10000004609

Public Conversations Project. (2011). Constructive conversations about challenging times: a guide to community dialogue. Watertown: Author. https://www.whatisessential.org/sites/default/files/PCP_Guide\%20to\%20Community \%20Dialogue.pdf 
Rego, W. D. L., \& Pinzani, A. (2013). Liberdade, dinheiro e autonomia. O caso da Bolsa Família. Revista de Ciências Sociais - Política \& Trabalho, (38), 21-42. http://periodicos.ufpb.br/ojs/index.php/politicaetrabalho/article/view/15029/9376

Santos, M. C. M., Gouveia Junior, A., Oliveira, P. R. M., Melo, D. R. A., \& Souza, W. A. R. (2014). A voz do beneficiário: uma análise da eficácia do Programa Bolsa Família. Revista de Administração Pública, 48(6), 1381-1405. https://doi.org/10.1590/0034-76121663

Simões, P., \& Soares, R. B. (2012). Efeitos do Programa Bolsa Família na fecundidade das beneficiárias. Revista Brasileira de Economia, 66(4), 445-468. https://doi.org/10.1590/S0034-71402012000400004

Souza, L. V., \& Moscheta, M. S. (2016). Ética e diferença no processo de pesquisa com grupo de conversações públicas. Athenea Digital, 16(3), 327-346. https://doi.org/10.5565/rev/athenea.1829

Souza, L. V., Oliveira, C. C. B., Silva, M. R., Andrade, L. C. S., \& Martins, M. A. (2014). Construção de uma prática grupal em uma unidade básica de saúde. In C. GuanaesLorenzi, M. Moscheta, C. M. Corradi-Webster, \& L. V. Souza (Orgs.), Construcionismo Social: discurso, prática e produção do conhecimento (pp. 187- 216). Rio de Janeiro: Instituto Noos.

Spink, M. J. (2010). Linguagem e produção de sentidos no cotidiano. Rio de Janeiro: Centro Edelstein de Pesquisas Sociais. http://books.scielo.org/id/w9q43

Spink, M. J., \& Medrado, B. (2013). Produção de sentidos no cotidiano: uma abordagem teórico-metodológica para análise das práticas discursivas. In M. J. Spink (Org.), Práticas discursivas e produção de sentidos no cotidiano: aproximações teóricas e metodológicas (pp. 22-41). São Paulo: Cortez.

Tavares, P. A. (2010). Efeito do Programa Bolsa Família sobre a oferta de trabalho das mães. Economia e Sociedade, 19(3), 613-635. https://doi.org/10.1590/S010406182010000300008

Trevisani, J. J. D., Burlandy, L., \& Jaime, P. C. (2012). Fluxos decisórios na formulação das condicionalidades de saúde do programa bolsa família. Saúde e Sociedade, 21(2), 492509. https://doi.org/10.1590/S0104-12902012000200021

Recebido em: 5/7/2018

Aprovado em: 23/10/2018 